\title{
Functionality and acceptability of a novel non-invasive neonatal heart rate monitoring device: a qualitative study of healthcare professionals
}

\author{
Oana Anton (D) , ${ }^{1}$ Ramon Fernandez, ${ }^{1,2}$ Elizabeth Rendon-Morales, ${ }^{3}$ \\ Rodrigo Aviles-Espinosa, ${ }^{3}$ Christina J Jones, ${ }^{4}$ Heike Rabe ${ }^{1,2}$
}

\begin{abstract}
- Additional material is published online only. To view please visit the journal online (http://dx.doi.org/10.1136/ bmjinnov-2019-000378).
\end{abstract}

${ }^{1}$ Department of Neonatology, Brighton and Sussex University Hospitals NHS Trust, Brighton, UK

${ }^{2}$ Academic Department of Paediatrics, Brighton and Sussex Medical School, Brighton, UK ${ }^{3}$ Robotics and Mechatronics Systems Research Center, School of Engineering and Informatics, University of Sussex, Brighton, UK

${ }^{4}$ Department of Psychology, Faculty of Health and Medical Sciences, University of Surrey, Guildford, UK

\section{Correspondence to}

Dr Oana Anton, Department of Neonatology, Brighton and Sussex University Hospitals NHS Trust, Brighton BN25BE, UK; 0. anton@nhs.net

Received 19 July 2019 Revised 26 December 2019 Accepted 4 June 2020

\section{Check for updates}

(C) Author(s) (or their employer(s)) 2020. No commercial re-use. See rights and permissions. Published by BMJ.

\section{To cite: Anton $\mathrm{O}$, Fernandez R, Rendon- Morales E, et al. BMJ Innov Epub ahead of print: [please include Day Month Year]. doi:10.1136/ bmjinnov-2019-000378}

\begin{abstract}
Background Detecting neonatal heart rate rapidly and accurately at birth is essential if resuscitation is required. The Neo-Sense prototype provides a quick, non-invasive method to measure neonatal heart rate at birth based on electric potential sensing technology. The study aimed to inform the prototype design process by exploring the required features and usability of this novel device among healthcare professionals.
\end{abstract}

Methods Face-to-face, semistructured interviews were conducted with healthcare professionals involved in the immediate care of babies at birth: paediatricians, midwives and neonatal nurses. Interviews were audio-recorded and subsequently transcribed verbatim. Two independent researchers coded and extracted the emerging categories and performed a thematic content analysis.

Results In total, 21 participants were interviewed, 7 from each professional group. Participants expressed a positive attitude towards the novel prototype. The three main themes extracted were anticipated limitations, advantages and suggestions for development and usage. Participants preferred a device that is easy to use and attach, one which is positioned in a mattress or pad, maintaining also the option of being mobile. Education was considered to have a key role in addressing staff anxiety. The ideal features most frequently mentioned were speed of assessment, reliability and accuracy. Conclusions The study enabled a better understanding of the perceived barriers and facilitators to developing a new heart rate monitoring device. The development of a quick and accurate device would have immense implications for clinical practice and the potential to improve neonatal mortality and morbidity.

\section{Key points}

- At the time of a baby's birth, midwives and neonatal staff are keen to listen to the baby's heart to determine the heart rate and to make sure the baby adapts well to a life outside the uterus.

- Listening to the baby's heart beat and detecting it can be quite difficult especially if the rate is low and the baby is unwell and in need of breathing support.

- This study aimed to inform the prototype development of a novel non-invasive sensor (Neo-Sense) to detect rapidly and accurately the heart rate in babies at birth.

What is known on the subject

- There are multiple established methods as well as novel technologies to determine heart rate in newborn babies.

- Electrocardiography and pulse oximetry are both more precise than palpation and auscultation, but studies have shown that the time elapsed from birth to successful establishment of heart rate detection and display often exceeds 1-2 min.

- Novel less invasive technologies have great potential to replace established methods, but a key stage in their development is staff involvement to ascertain a set of ideal features and improve acceptance.

What this study adds

- This qualitative study offers valuable insight into healthcare professionals' views and perceptions on current methods used to detect heart rate on babies at birth, but also the most important requirements for a new heart rate sensor (Neo-Sense) by ascertaining a set of 'ideal features'. 


\section{BACKGROUND}

Heart rate is the most important clinical indicator to evaluate the cardiorespiratory status of a newborn and is used to guide resuscitation efforts. ${ }^{1}$ Heart rate during the first minutes of life in infants needing resuscitation may be a predictor of neonatal mortality and moderate to severe brain injury in those who survive. ${ }^{2}$

The literature describes several established methods to determine heart rate at birth, such as palpation, auscultation, pulse oximetry and electrocardiography (ECG). ECG remains the gold standard to continuously monitor an infant's heart rate in the neonatal intensive care unit (NICU). ${ }^{3}$ Both ECG and pulse oximetry are considered to be more precise than auscultation and palpation, ${ }^{34}$ but studies have shown that the time from birth to successful heart rate display using these devices often exceeds $1-2$ min. $^{56}$

Novel techniques are increasingly mentioned in the literature, but each modality has its own limitations, most commonly movement artefacts. ${ }^{47}$

Special consideration is given in the literature to noninvasive methods which minimise noxious stimuli and infection pathways, especially for vulnerable preterm infants. $^{4}$

Our research group is collaborating to offer a quick and accurate technological solution to detecting heart rate at birth. The Neo-Sense prototype is based on electric potential sensing technology. This technology was invented at the University of Sussex as a non-invasive sensing technology. ${ }^{8}$ The sensor is a feedback-enhanced and stabilised electrometer-based amplifier that operates on displacement current measurements.

We considered different options when building the prototype, such as embedding the sensors into a neonatal mattress or imprinting them on a textile in a pad or a strap. Figure 1 is a diagram of the proposed prototype incorporated into a mattress.

For all options, the baby would be placed in close contact but without the need to attach the sensor to the baby's skin. If the sensors are incorporated into the mattress, the baby will be placed on top of the sensor. Neo-Sense has the potential to improve clinical practice in a resuscitation scenario by eliminating the

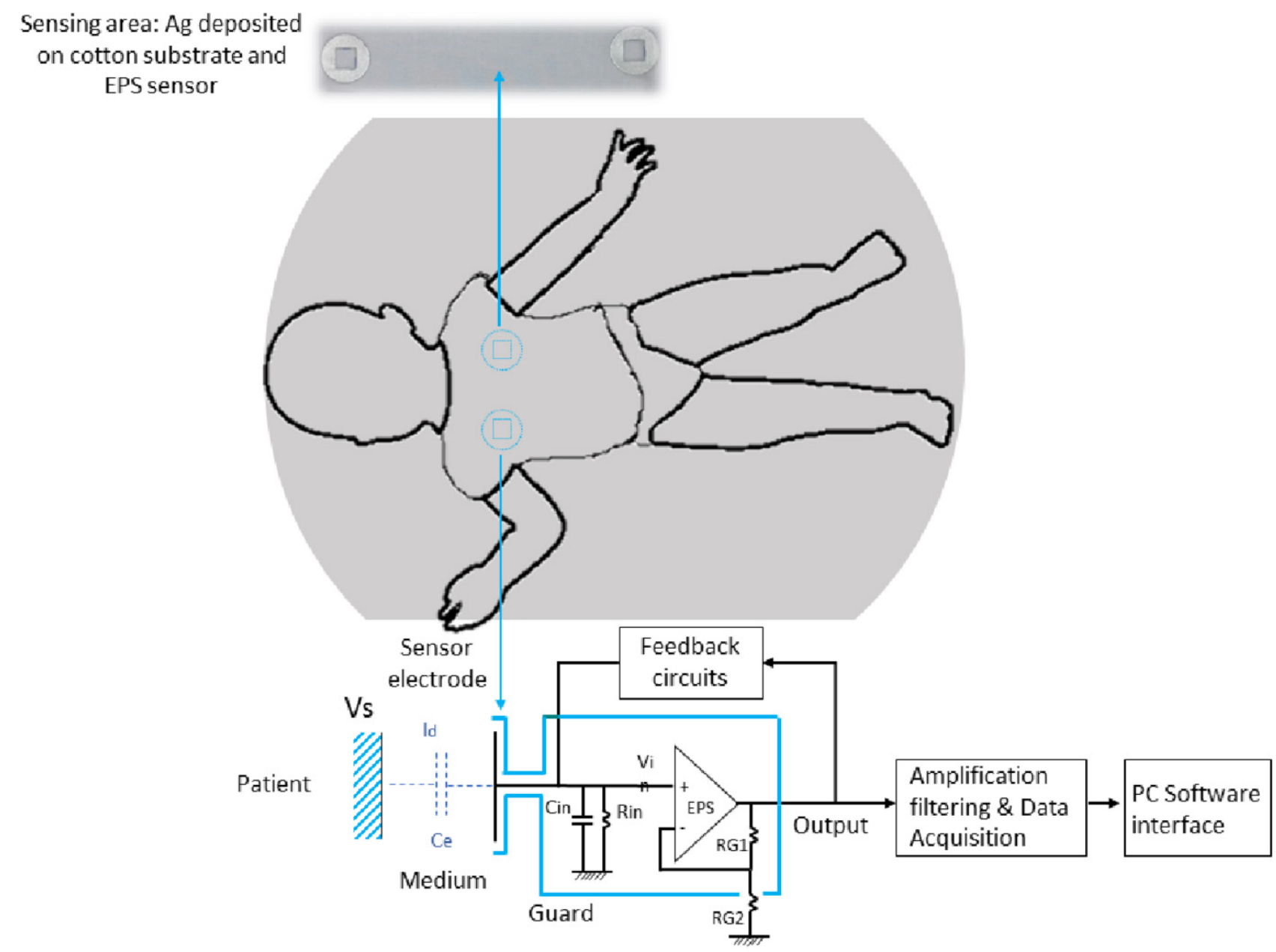

Figure 1 Schematic of the smart-mattress (top) and the sensor design implementing the EPS (bottom). Ag, silver; Ce, capacitance; Cin, capacitance in; EPS, electric potential sensor; Id, inductance; Rin, resistance in; RG1 and RG2, resistance; Vin, input voltage; Vs, voltage sample. 
considerable delay caused by the time to attach a heart rate monitoring sensor.

\section{Aims of the study}

The study aims were to inform the Neo-Sense prototype design process by exploring healthcare professionals' perspectives on the required features and usability of this novel device. This would enable us to ascertain the most important requirements for the Neo-Sense sensor.

\section{METHODS}

\section{Recruitment and consent}

The qualitative study was conducted in a level 3 NICU and a labour ward. As advised by the Hospital Trust Research and Development Department, the study was considered a service evaluation project as it explores the opinions of healthcare professionals, in an effort to improve heart rate monitoring in newborn babies. The project was registered with the Trust Clinical Governance Department as per hospital policy. The study was exempt from ethical approval and this decision was supported by the UK Health Research Authority tool kit. ${ }^{9}$ All participants provided written consent to be interviewed. Data from the interviews were anonymised and stored securely on a password-protected computer. Participants were healthcare professionals involved in the immediate care of babies at birth: paediatricians, midwives and neonatal nurses.

\section{Interviews}

Using purposeful sampling for face-to-face, semistructured interviews, we explored the features of the novel sensor. ${ }^{9}$ Interviews were held in a quiet and private environment away from clinical areas. The interview guide was designed based on the exploratory literature review on heart rate detection methods in neonates (online supplementary e-Table 1). ${ }^{10}$

To stimulate discussion, participants were presented with a series of pictures of term and preterm manikins having attached ECG, pulse oximetry and the proposed Neo-Sense prototype in incipient stages. Participants were offered several options regarding positioning. Different possibilities such as having the sensor incorporated into a mattress, in textile pad or a strap around the baby were discussed. The researcher summarised the main features of the prototype and its functions. Each interview was audio-recorded, anonymised and transcribed verbatim.

\section{Data analysis}

Thematic content analysis using Burnard's framework was conducted on the interview transcripts. ${ }^{11} 12$ This stage-by-stage process of analysing qualitative data enables the researcher to initially extract as many categories as possible. ${ }^{11} 12$ These categories are then used to generate themes and subthemes that are further explored in subsequent interviews. Microsoft Excel was used for data management. Two independent researchers coded and extracted the emerging categories, with several peer debriefing sessions to agree on categorisation and the final themes.

\section{RESULTS}

\section{Participants' characteristics}

In total 21 participants were interviewed, 7 from each professional group: paediatricians, midwives and neonatal nurses. Both junior and senior members of staff were included (table 1).

Three major themes emerged from the interviews: perceived limitations, advantages of the novel sensor and suggestions for further development and usability. Each of these themes had several subthemes (figure 2).

\section{Perceived limitations of Neo-Sense sensor}

Size

Some participants were concerned that the prototype looks big on the preterm manikin and that it would cover the baby's chest for the pad option. This ultimately could affect the visual cues during a resuscitation scenario.

At the moment it looks quite thick but as you say it is a prototype. (1A)

It looks good, but it is big and it will cover a lot of area on the baby's body. (4A)

It looks big and bulky compared with ECG. (20A)

When it is on the baby, I am worried that it covers the chest. (5A)

Placement and positioning

The second subtheme referred to perceived difficulties with positioning and placement. This subtheme has its own subcategories which were based on the different placement options. Among the most frequently mentioned disadvantages were movement artefact and the possibility of causing discomfort (table 2).

\section{Staff anxiety with unfamiliar device}

Apart from limitations due to size and placement, there were perceived difficulties linked to staff anxiety. These were subdivided into different categories. The main concerns were aimed at the babies' comfort and safety, but some participants were intrigued by the device utilisation features, placement and connectivity (table 3).

To address staff anxiety, most of the participants suggested targeted education and the use of visual aids such as instruction sheets on the resuscitaire or a set of instructions preattached to the device:

I am sure after training we should be ok. It might be ideas to have a little instruction sheet on the resuscitaire so people learn how to do it. Having little cards on resuscitaires with instructions cause a lot of people come to labour ward after a long time so having instructions will help. (12A) 


\section{MEDICAL DEVICES}

\begin{tabular}{|c|c|c|c|c|}
\hline Study ID & Role & Years of experience in current role & Sex & Frequency of attending deliveries \\
\hline $1 \mathrm{~A}$ & Neonatal research nurse & 8 & Female & 3-4 times/year \\
\hline $2 \mathrm{~A}$ & Paediatric senior house officer & 3 & Female & 15 times/week \\
\hline $3 \mathrm{~A}$ & Neonatal senior staff nurse & 12 & Female & 1 time/month \\
\hline $4 \mathrm{~A}$ & Neonatal senior staff nurse & 11 & Female & $N / A$ \\
\hline $5 \mathrm{~A}$ & Neonatal senior staff nurse & 7 & Female & 2 times/week \\
\hline $6 \mathrm{~A}$ & Neonatal consultant & 13 & Male & $N / A$ \\
\hline $7 \mathrm{~A}$ & Neonatal consultant & 11 & Female & $N / A$ \\
\hline $8 \mathrm{~A}$ & Senior neonatal sister & 25 & Female & 1 time/month \\
\hline $9 \mathrm{~A}$ & Paediatric senior house officer & 3 & Female & 1-5 times/day \\
\hline $10 \mathrm{~A}$ & Midwife & 2 & Female & 1 time/day \\
\hline $11 \mathrm{~A}$ & Midwife & 1 & Female & 3 times/day \\
\hline $12 \mathrm{~A}$ & Midwife & 2 & Female & 2 times/week \\
\hline $13 \mathrm{~A}$ & Senior midwife & 9 & Female & 6-8 times/week \\
\hline $14 \mathrm{~A}$ & Advanced neonatal nurse practitioner & 11 & Female & 2-3 times/week \\
\hline $15 \mathrm{~A}$ & Senior neonatal sister & 20 & Female & $N / A$ \\
\hline $16 \mathrm{~A}$ & Neonatal consultant & 4 & Male & 40-50 times/year \\
\hline $17 \mathrm{~A}$ & Paediatric registrar & 5 & Female & 2-3 times/week \\
\hline $18 \mathrm{~A}$ & Community midwife & 4 & Female & 1-2 times/week \\
\hline $19 \mathrm{~A}$ & Midwife & 2 & Female & $N / A$ \\
\hline $20 \mathrm{~A}$ & Senior midwife & 13 & Female & 2 times/week \\
\hline $21 \mathrm{~A}$ & Senior neonatal sister & 9 & Female & $N / A$ \\
\hline
\end{tabular}

N/A, not available.

Cost

One of the participants considered the cost of Neo-Sense:

Having the sensor in a textile, it gets wet and you will have to change it very often. I am not sure how

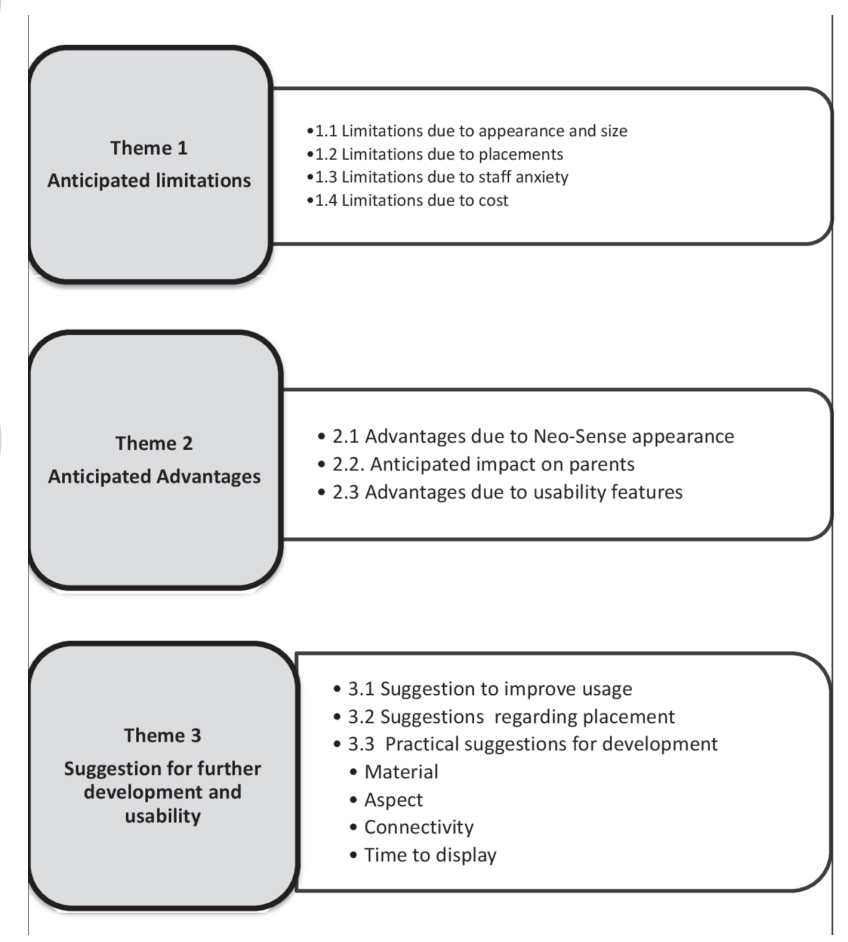

Figure 2 Major themes and subthemes emerging from the interviews. cost-effective that would be; I worry about the cost, disposability and cleanliness. (3A)

Several participants also discussed whether the sensor should be single use or reusable, which has a direct impact on cost. Opinions were divided, with some participants opting for reusable sensors, as these are better for the environment, and others single use or single sensor per baby for longer monitoring.

I would worry about cost, disposability and cleanliness because if it is the mattress the cleaning it might be a complex process. (14A)

\section{Perceived advantages of Neo-Sense sensor}

Overall positive attitudes towards Neo-Sense were observed due to all the perceived advantages. These were further explored under the second major theme and its related subthemes (figure 2).

\section{Neo-Sense appearance}

The Neo-Sense appearance made a significant impact on participants. The anticipated advantages were attributed to its non-obtrusive, simple nature and the lack of visible wires.

It looks much nicer probably for the baby as well he doesn't have anything attached. (1A)

It is not like a scary medical device. (11A)

It looks tidy and simple; it looks good on the mattress. (4A)

It is fairly unobtrusive there isn't much in the way. (8A) 
Table 2 Anticipated limitations due to placement of Neo-Sense

\begin{tabular}{|c|c|c|c|c|c|}
\hline Due to movement & Due to size of the baby & $\begin{array}{l}\text { If incorporated into a } \\
\text { mattress }\end{array}$ & If anterior placement & $\begin{array}{l}\text { If strapped to the } \\
\text { baby }\end{array}$ & If posterior placement \\
\hline $\begin{array}{l}\text { "My concerns are that the } \\
\text { baby is moving around on } \\
\text { it. So, what I want is not to } \\
\text { keep on touching the baby } \\
\text { to position." (1A) } \\
\text { "Loss of contact with the } \\
\text { sensor with movement." } \\
\text { (11A) }\end{array}$ & $\begin{array}{l}\text { "I am not sure if the one in } \\
\text { the mattress will pick up the } \\
\text { HR [heart rate] in very tiny } \\
\text { babies or in a big baby." } \\
\text { (3A) } \\
\text { "Preterm babies will have } \\
\text { to go in a plastic bag, what } \\
\text { is the impact of fluid on the } \\
\text { sensor." (16A) } \\
\text { "The baby is at risk of } \\
\text { hypothermia." (16A) }\end{array}$ & $\begin{array}{l}\text { "It makes it difficult to know } \\
\text { where to put the baby. They } \\
\text { are not always going to } \\
\text { lie on the same side of the } \\
\text { mattress." (5A) } \\
\text { "How hard would it be to } \\
\text { replace rather than just } \\
\text { being an external device." } \\
\text { (9A) } \\
\text { "It wouldn't allow you to } \\
\text { give the baby to mum and } \\
\text { dad, to do skin to skin, } \\
\text { breastfeed the baby; you } \\
\text { wouldn't be able to comfort } \\
\text { the baby." (13A) } \\
\text { "If disposable it might } \\
\text { become problematic." (14A) }\end{array}$ & $\begin{array}{l}\text { "If it is on the front it is } \\
\text { occluding baby's abdomen } \\
\text { and chest." (5A) } \\
\text { "It might interfere with } \\
\text { phototherapy." (14A) } \\
\text { "Most babies have lines that } \\
\text { are around the umbilicus." } \\
(14 \mathrm{~A})\end{array}$ & $\begin{array}{l}\text { "The straps will get wet." } \\
(6 \mathrm{~A}) \\
\text { "It makes it dirty, so you } \\
\text { have to have wipe able } \\
\text { straps, but they also have } \\
\text { to be stretchable so from } \\
\text { cleaning point of view it } \\
\text { makes it trick." (17A) } \\
\text { "The babies might be } \\
\text { restricted." (12A) }\end{array}$ & $\begin{array}{l}\text { "You might have } 2 \text { towels } \\
\text { when the baby is being } \\
\text { brought to you." (7A) } \\
\text { "We would have to keep } \\
\text { an eye on the back, so it } \\
\text { doesn't mark the baby." } \\
\text { (8A) }\end{array}$ \\
\hline
\end{tabular}

It is quite small and non-invasive; it doesn't look that it can cause any harm. (9A)

The material textile one looks nicer. (13A)

Healthcare professionals acknowledged that the Neo-Sense appearance was also likely to have a positive impact on parents:

I think as a parent going to see your child that is in a scary place anyhow it looks better than having all these wires. They are doing the same thing but visually it makes them think that their baby is very sick. (10A)

It doesn't look scary from parents' point of you. It doesn't have that many wires. It can be hidden. (18A)

\section{Usability and placement features}

In terms of utilisation, participants perceived it to be easy to use, to set up and beneficial in case of emergency situations. Positioning of the device in the mattress but also having the option of being mobile is considered an advantage of this proposed novel device (table 4).

One of the participants considered having the sensor strapped to the baby as an advantage.

It is the easiest as you can customise the size for each baby and wrap it around with Velcro you can get a snug fit. (11A)

\section{Comfort}

Two of the biggest anticipated advantages would be not affecting the preterm skin and reducing the stress and painful stimuli on babies.

The advantages will be that it will be quicker to move baby and transfer into a transport incubator. (3A)

Another advantage is that for very preterm babies we tend not to use ECG because they are so tiny so

Table 3 Anticipated difficulties related to staff anxiety

\begin{tabular}{|c|c|c|c|}
\hline Baby-related & Usage & Placement & Being a wireless device \\
\hline $\begin{array}{l}\text { "Does it have the potential to cause any } \\
\text { harm to the baby?" ( } 9 \mathrm{~A}) \\
\text { "Will it be heating up and affect baby's } \\
\text { skin?" ( } 9 \mathrm{~A}) \\
\text { "That would be my concern baby's } \\
\text { comfort." (1A) } \\
\text { "Baby is at risk of hypothermia." (16A) } \\
\text { "There will be different size babies." } \\
\text { (17A) } \\
\text { "What if you have a term baby that is } \\
\text { covered in meconium does the probe still } \\
\text { pick up?" (18A) }\end{array}$ & $\begin{array}{l}\text { "Is an ECG } \\
\text { [electrocardiography] trace } \\
\text { going to make a difference? For } \\
\text { it to come into routine practice } \\
\text { it would have to change my } \\
\text { practice." (6A) } \\
\text { "I would be worried if there } \\
\text { is a need for extra steps to be } \\
\text { done." (2A) } \\
\text { "Would it interfere with other } \\
\text { pieces of equipment or be } \\
\text { affected by movement?" (9A) } \\
\text { "It is an electrical device so it } \\
\text { should be safe." (19A) }\end{array}$ & $\begin{array}{l}\text { "Is it going to read through the } \\
\text { towel?" (3A, 7A) } \\
\text { "Would it work through sheets?" } \\
\text { (18A) } \\
\text { "How does it work if the baby is } \\
\text { placed in a plastic bag, will it affect } \\
\text { the accuracy of the reading?" (8A) } \\
\text { "Does it have to be under the } \\
\text { chest?" (17A) } \\
\text { "Would you be able to see it through } \\
\text { the mattress, though the sheet or } \\
\text { do you have to guess where exactly } \\
\text { it is? Cleaning might be a complex } \\
\text { process." (8A) } \\
\text { "I suppose that if you have a } \\
\text { device under a baby you would be } \\
\text { concerned it may cause sores or } \\
\text { pressure affecting skin integrity." } \\
\text { (9A) }\end{array}$ & $\begin{array}{l}\text { "Wireless devices drop out they are not } \\
\text { reliable." (9A) } \\
\text { "It would be really clever, but the } \\
\text { concern is does it link to the internet?" } \\
(10 \mathrm{~A}) \\
\text { "What would happen if the wireless } \\
\text { system went down, how would it back } \\
\text { itself up?" (10A) } \\
\text { "Would it have to be fully charged, } \\
\text { to be sure we have a stable wireless } \\
\text { connection?" (10A) }\end{array}$ \\
\hline
\end{tabular}


Table 4 Perceived advantages of Neo-Sense

Advantages due to usability and placement features

Advantages if incorporated into the mattress

"I think it will be easy to use especially downstairs in a delivery if you just need to place the baby on top of it. It seems to be very quick and easy." (3A)

"It looks that it would be easy to use as you don't need to physically attach it to the

baby. There won't be any difficulties if the baby is not dry enough." (5A)

"It seems quite simple which will be good if you are in an emergency situation if it gives you a quick reading." (9A)

"If you just have to lay a baby on it that seems amazing very simple anybody can use it, especially in an emergency scenario when you have to do a lot of things to the baby as well. If you could just lay the baby on it and have a reading rather than sticking the pulse oximetry, that would be really good, very clever. I think it is amazing, anybody would be able to use just place the baby on it and it picks up the heart rate rather than fiddling with the baby when other things are going on as well." (10A)

"I think that the mattress would be incredibly easy if it works as you just have to lay the baby on it." (11A)

"In the mattress, it can't go missing; I think that would be an advantage." (18A)

"It looks comfortable and easy to use." (20A)

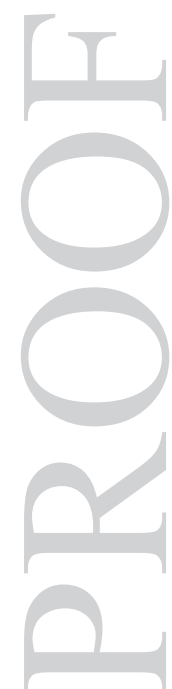

if they have an arterial line and a saturation probe, we use that for their HR [heart rate] and we don't bother with ECG. This sensor could get a decent ECG trace with a rhythm for those babies that we can't use ECG leads. (5A)

As Neo-Sense does not have to attach to the baby's skin, it does not have to be removed during further investigations such as $\mathrm{X}$-rays.

That probably is quite nice when babies are having X-rays you would not have to take ECG leads off. So, I think that would be really good, all you have to do it is just slip it off. If it is not sticky like ECG leads it would not affect the smaller babies, because you sometimes injure the skin when you do that. That is a good point. (8A)

\section{Ideal features for Neo-Sense}

The further aim of our study was to ascertain the most important requirements for the proposed device. After describing the perceived limitations and advantages, participants were prompted to offer suggestions for further development to improve uptake and usage.

\section{Functionality}

Participants reported a preference for a device that is "easy to use," "easy to attach," "self-explanatory" and "easy to maintain" (13A). At the same time, it should "have instructions for me to know exactly how to use it in an emergency situation as easy to understand as possible" (5A). Another important point raised was that it should not need changing position all the time and be "the least disruptive to the care of the baby" (1A).

When asked about its ideal features, participants mainly mentioned baby's comfort, ease of use, reliability, speed of assessment, flexibility to go anywhere on the body and accessibility (online supplementary e-Table 2).

\section{Placement and positioning}

The preferred placement was underneath the baby. Two participants suggested anterior placement in the case of premature babies or if the device was very small. Strapping was largely considered with the sensor mainly posteriorly especially for term babies, ongoing monitoring and to facilitate skin to skin with parents. Using a pad was mentioned by two participants, ideally a single pad slipped posteriorly.

To help with positioning, participants have made several suggestions especially if the sensor was to be incorporated into the mattress (online supplementary e-Table 2).

Participants were asked to give a rationale behind their choice of placement (online supplementary e-Table 3).

\section{Design preferences}

Participants had other practical suggestions to improve the Neo-Sense device with regard to its material, aspect, connectivity and time to display. These categories spanned from improved features in terms of comfort for the baby, immediacy of results to improve clinical reporting as well as aesthetic improvements. They preferred a soft material with a child-friendly pattern that connects via Bluetooth to a monitor and as quick as possible to display a result (e- online supplementary e-Table 4).

\section{DISCUSSION}

In those babies who need significant help with transition after birth, heart rate has an essential role not only in guiding resuscitation efforts but also as a prognostic factor. ${ }^{213} 14$ There is an urgent need for a non-invasive technological solution to offer a quick and accurate heart rate measurement at birth. Furthermore, a flexible, portable device will support other interventions such as placental transfusion. The benefits of delayed cord clamping are well recognised in the literature and better monitoring will encourage its uptake on a global scale. ${ }^{14} 15$

Ultimately, Neo-Sense has the potential to become a wireless device which will enable using this technology remotely, to include different settings such as community birthing centres and developing countries. Future research studies in these areas could assess the 
impact on short-term and long-term neonatal health outcomes.

Participants initially commented on appearance and size and recognised that choosing the adequate size would be a key factor. Its minimal contact, nonadhesive features were perceived as an essential advantage. One of the goals of novel technology, as highlighted in multiple studies, is to minimise invasive patient contact and maintain the natural skin barrier. This would reduce skin damage and susceptibility to infection. In addition, these sensors should offer increased comfort by reducing mechanical and painful stimuli. ${ }^{16-20}$

The preferred placement was underneath the baby incorporated into a mattress, but having the option of a mobile, flexible device was seen as an advantage. Each option of placement has its limitations. Participants expressed careful consideration of the baby's comfort and offered solutions to counteract these perceived limitations.

Healthcare professionals expressed anxiety towards this unfamiliar device utilisation features, its placement and connectivity. This should be addressed early in the design process and has an essential role in accepting the novel device for wider use. The anticipated limitations are in keeping with those mentioned in the literature. Other studies have suggested that the difficulties with novel sensors were mainly due to movement artefact, bad sensor coupling, intermittent measurement and poor-quality recordings. ${ }^{17-20}$ The majority of participants suggested addressing limitations and staff anxiety by providing targeted education and the use of visual aids with utilisation instructions.

Despite these anticipated limitations, we had an overall positive attitude towards the proposed novel device. This is due to multiple perceived advantages. Appearance was considered non-invasive, simple and with less visible wires. The potential positive impact on parents due to its non-obtrusive aspect is an important asset. Furthermore, the device is considered "easy to use, set-up and good in emergency situations" (3A).

Using a theoretical framework for acceptability as described by Sekhon et $a l^{21}$ can guide the design of future comparison studies, from proof of concept, to evaluation and implementation studies. Acceptability would be influenced by the prototype's ability to accomplish the most frequently mentioned ideal features. Nevertheless, careful considerations should be given to the prospective and retrospective cognitive and emotional responses towards the use of this new device. These can be further explored in future qualitative or quantitative studies.

The strength of this study is that it offers a multidisciplinary healthcare professionals' perspective on the difficulties and advantages of this proposed method to detect heart rate on babies at birth.

The limitations are due to the influence of the researchers' reflexivity. ${ }^{22}$ There is always an element of bias due to researchers' own opinions of the device, the relationship with the participants and the influence of all these factors on the generated data. Further exploration of the anticipated advantages and limitations of the proposed prototype required a good understanding of the device features. This was enhanced through a continuous collaboration between the research group partners. ${ }^{23}$

\section{CONCLUSIONS}

The study enabled a better understanding of the perceived barriers and facilitators to developing a new heart rate monitoring device. Healthcare professionals' involvement is a key component of this process offering vital information on its acceptability and functionality. For Neo-Sense to be accepted it has to overcome the anticipated limitations and prove its speed of assessment, reliability and accuracy when compared with the current methods, pulse oximetry and ECG. Further studies will be necessary at different stages through the development process. An accurate and quick technological solution to determine heart rate on babies at birth would have immense implications for clinical practice and potential to improve neonatal mortality and morbidity.

Contributors OA conceptualised the study, conducted the faceto-face interviews and transcribed verbatim. Data extraction and analysis were a collaborative effort. HR, RF and CJJ conceptualised the study, contributed to data analysis, reviewed and revised the manuscript. ER-M and RA-E provided technical advice, reviewed and revised the manuscript. All authors approved the final manuscript as submitted and agree to be accountable for all aspects of the work.

Funding The study was partially funded by the Rockinghorse Appeal and The Early Birth Association charities.

Competing interests None declared.

Patient consent for publication Not required.

Provenance and peer review Not commissioned; externally peer reviewed.

Data availability statement All data relevant to the study are included in the article or uploaded as supplementary information. Data generated by our research can be made available upon publication of our article.

ORCID iD

Oana Anton http://orcid.org/0000-0001-8074-7451

\section{REFERENCES}

1 Perlman JM, Wyllie J, Kattwinkel J, et al. Part 7: neonatal resuscitation: 2015 international consensus on cardiopulmonary resuscitation and emergency cardiovascular care science with treatment recommendations. Circulation 2015; 132:S120-66.

2 Saugstad OD, Ramji S, Rootwelt T, et al. Response to resuscitation of the newborn: early prognostic variables. Acta Paediatr 2005;94:890-5.

3 Phillipos E, Solevåg AL, Pichler G, et al. Heart rate assessment immediately after birth. Neonatology 2016;109:130-8.

4 Kevat AC, Bullen DVR, Davis PG, et al. A systematic review of novel technology for monitoring infant and newborn heart rate. Acta Paediatr 2017;106:710-20. 


\section{MEDICAL DEVICES}

5 Mizumoto H, Tomotaki S, Shibata H, et al. Electrocardiogram shows reliable heart rates much earlier than pulse oximetry during neonatal resuscitation. Pediatr Int 2012;54:205-7.

6 O'Donnell CPF, Kamlin COF, Davis PG, et al. Feasibility of and delay in obtaining pulse oximetry during neonatal resuscitation. J Pediatr 2005;147:698-9.

7 Anton O, Fernandez R, Rendon-Morales E, et al. Heart rate monitoring in newborn babies: a systematic review. Switzerland: (C) 2019 S. Karger AG, Basel. Neonatology 2019:1-12.

8 Prance R, Harland C. EPS Patent US8264247B2, 2012. Available: https://patents.google.com/patent/US8264247B2

9 Authority HR. Studies involving the NHS in England decision tools, 2018. Available: http://www.hra-decisiontools.org.uk/ ethics/

10 Anton O, Fernandez R, Rendon-Morales E, et al. Heart rate monitoring in newborn babies: a systematic review. Neonatology 2019;116:199-210.

11 Burnard P, Gill P, Stewart K, et al. Analysing and presenting qualitative data. Br Dent J 2008;204:429-32.

12 Burnard P. A method of analysing interview transcripts in qualitative research. Nurse Educ Today 1991;11:461-6.

13 Wyllie J, Perlman JM, Kattwinkel J, et al. Part 11: neonatal resuscitation: 2010 international consensus on cardiopulmonary resuscitation and emergency cardiovascular care science with treatment recommendations. Resuscitation 2010;81:e260-87.

14 Anton O, Jordan H, Rabe H. Strategies for implementing placental transfusion at birth: a systematic review. Birth 2019;46:411-27.

15 Rabe H, Gyte GM, Díaz-Rossello JL, et al. Effect of timing of umbilical cord clamping and other strategies to influence placental transfusion at preterm birth on maternal and infant outcomes. Cochrane Database Syst Rev 2019;9:Cd003248.

16 Marchionni P, Scalise L, Ercoli I, et al. An optical measurement method for the simultaneous assessment of respiration and heart rates in preterm infants. Rev Sci Instrum 2013;84:121705.

17 Atallah L, Serteyn A, Meftah M, et al. Unobtrusive ECG monitoring in the NICU using a capacitive sensing array. Physiol Meas 2014;35:895-913.

18 Kato T, Ueno A, Kataoka S, et al. An application of capacitive electrode for detecting electrocardiogram of neonates and infants. Conf Proc IEEE Eng Med Biol Soc 2006;1:916-9.

19 Nukaya S, Sugie M, Kurihara Y, et al. A noninvasive heartbeat, respiration, and body movement monitoring system for neonates. Artif Life Robot 2014;19:414-9.

20 Sato S, Ishida-Nakajima W, Ishida A, et al. Assessment of a new piezoelectric transducer sensor for noninvasive cardiorespiratory monitoring of newborn infants in the NICU. Neonatology 2010;98:179-90.

21 Sekhon M, Cartwright M, Francis JJ. Acceptability of healthcare interventions: an overview of reviews and development of a theoretical framework. BMC Health Serv Res 2017;17:88-101.

22 Richards H, Emslie C. The 'doctor' or the 'girl from the University'? Considering the influence of professional roles on qualitative interviewing. Fam Pract 2000;17:71-5.

23 Aviles-Espinosa R, Rendon-Morales E, Luo Z, et al. NeoSENSE: a non-invasive smart sensing mattress for cardiac monitoring of babies. 2019 IEEE sensors applications symposium (SAS) 2019. 